\title{
Towns and Trails Drive Carnivore Connectivity using a Step
}

\section{Affiliations}

- JW, RB: Park Canada, Banff National Park Resource Conservation. PO Box 900, Banff,

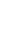
Alberta, Canada. T1L 1K2

- MH: Wildlife Biology Program, Department of Ecosystem and Conservation Sciences, W.A. Franke College of Forestry and Conservation, University of Montana, 32 Campus Drive, Missoula, MT, USA.59801

- AF: Department of Biology, Faculty of Science, University of British Columbia, Kelowna, BC, Canada. V1V 1V7

- JP: Alberta Environment and Parks, Kananaskis Region, 201, 800 Railway Avenue, Canmore, Alberta, Canada. T1W 1P1

\section{Abstract}

18 Global increases in human activity threaten connectivity of animal populations. Protection and

19 restoration of animal movement corridors requires robust models to forecast the effects of human

20 activity on connectivity. Recent advances in the field of animal movement ecology and step

21 selection functions offer new approaches for estimating connectivity. We show how a 
22 combination of hidden Markov movement models and step selection functions can be used to

23 simulate realistic movement paths with multiple behavioral states. Simulated paths can be used

24 to generate utilization distributions and estimate changes in connectivity for multiple land use

25 scenarios. We applied movement models to 20 years of grizzly bear (Ursus arctos) and gray wolf

26 (Canis lupus) data collected in and around Banff National Park, Canada. These carnivores

27 avoided areas near towns in all seasons, avoided areas of high trail density in most seasons, and

28 campgrounds during summer and fall. We simulated movement paths for three landscape

29 scenarios: reference conditions with no anthropogenic development, current conditions, and

30 future conditions with expanded town footprints and trail networks. We counted the number of

31 paths that crossed valley-wide, digital transects through mountain tourist towns of Banff and

32 Canmore, Alberta. We divided current and future crossing rates by the reference crossing rates to

33 estimate connectivity. Current connectivity rates ranged between 7 and $45 \%$ of reference values

34 with an average of $21 \%$ for grizzly bears and $25 \%$ for wolves. Potential town expansion and

35 increased development of trails further decreased connectivity an average of $6 \%$ in future

36 scenarios. Anthropogenic developments reduced the amount of available high quality large

37 carnivore habitat in the Bow Valley by an average of $14 \%$ under current conditions and $16 \%$

38 under future conditions. Our approach for estimating connectivity provides a robust and flexible

39 method for combining movement models with step selection analyses to estimate connectivity

40 for a variety of species.

\section{Key words}

43 connectivity, conservation, corridors, movement ecology, human development, resource

44 selection, step selection, utilization distribution 


\section{Introduction}

46 Global increases in human activity threatens wildlife populations and as a result, many

47 conservation programs have increased their focus on ecological connectivity (Hilty et al. 2020).

48 Connectivity analyses of animal movement are frequently used to identify likely dispersal routes

49 between populations (Fattebert et al. 2015, Zeller et al. 2018), seasonal migrations routes (e.g.

50 Fullman et al. 2021), and to highlight natural and anthropogenic pinch points to movement (i.e.

51 wildlife corridors) as priority areas for conservation (Chetkiewicz and Boyce 2009, Suraci et al.

52 2020). Within an animal's home range, wildlife corridors facilitate movements important for

53 reproduction, accessing seasonal resources, and predator-prey processes (Hebblewhite 2005,

54 Panzacchi et al. 2016). At broader scales, connectivity facilitates dispersal (Benz et al. 2016),

55 gene flow, and demographic rescue of subpopulations (Marrotte et al. 2017, Lamb et al. 2020). A

56 wide variety of approaches have been used to estimate connectivity of animal movements, with

57 varying degrees of success (Calabrese and Fagan 2004, Zeller et al. 2018). Emerging techniques

58 in the field of movement ecology offer new opportunities to develop stronger links between

59 movement behavior and estimates of connectivity (e.g. Hooten et al. 2020).

Movement models and step selection analyses offer a complementary approach for

61 estimating connectivity either from model predictions (Buderman et al. 2018, Hooten et al. 2020)

62 or from simulated paths (Palmer et al. 2011, Quaglietta and Porto 2019, Zeller et al. 2020). Step

63 selection analyses are a subset of spatial point-process models that are increasingly used to

64 estimate relative selection of resources (Fortin et al. 2005), to understand the effects of human

65 activity on animal movement behaviour (e.g. Suraci et al. 2019), and to create utilization

66 distributions (UDs) that predict spatial variation in intensity of habitat use (Signer et al. 2017).

67 Step selection analyses have become increasingly accessible for practitioners through the 
68 development of statistical packages in R (Avgar et al. 2016, Signer et al. 2019, Muff et al. 2020).

69 Several studies have incorporated step selection functions (SSFs) into connectivity analyses by

70 first creating spatial predictions of habitat use and then transforming predictions into resistance

71 layers for cost-distance or circuit theory analyses (Zeller et al. 2018, Brennan et al. 2020, Suraci

72 et al. 2020). Others have used the derived resistance surfaces to simulate animal movements

73 (Quaglietta and Porto 2019, Jayadevan et al. 2020, Zeller et al. 2020). For example, Merkle et al.

74 (2019) simulated movements directly from an SSF to forecast migration routes. Simulated

75 individual-based paths are appealing because they can incorporate sequential, probabilistic

76 movement decisions related to landscape features, speed of travel, and directional persistence

77 (Avgar et al. 2016). Moreover, simulating animal movements is considered the best practice for

78 generate unbiased UDs from SSFs (Signer et al. 2017). Simulations, while computational

79 intensive, can easily be applied to multiple land use scenarios. Movement simulations from SSFs

80 offer a promising method for assessing the cumulative effects of multiple landscape features on

81 animal movement paths, intensity of use, and connectivity.

82 Realistic simulations need to accommodate the underlying factors that influence animal

83 movement including seasonal (Zeller et al. 2019, Brennan et al. 2020, Zeller et al. 2020) and

84 temporal (Gaynor et al. 2018, Lamb et al. 2020) variability in resource selection and state-

85 specific movement behaviors (Michelot et al. 2016). For example, animals often have low

86 directional persistence and low speed of travel when feeding and resting in slow states and have

87 strong directional persistence and higher speed of travel when travelling in fast states (Fryxell et

88 al. 2008). Such behavioral states are overlooked in classical circuit theory and cost-distance type

89 connectivity models. And failure to incorporate behavioral state into SSFs can lead to biased

90 UDs, poor estimates of connectivity, and misidentification of wildlife corridors (Abrahms et al. 
91 2017). Finally, responses to human activity and estimates of connectivity can vary widely among

92 species (e.g. Rogala et al. 2011, Brennan et al. 2020, Nickel et al. 2020). From a conservation

93 perspective, focussing on the most sensitive species should increase connectivity for most other

94 wildlife (Meurant et al. 2018, Lamb et al. 2020).

95 Large carnivores are an important consideration for landscape-scale measures of

96 connectivity for a number of reasons. First, these iconic and charismatic species are often

97 selected as conservation 'flagship' and umbrella species, meaning they hold a particularly deep

98 value for the public and management agencies (Ray et al. 2013). Second, the potential threat of

99 carnivores to human safety requires a detailed understanding of how animals move through

100 human-dominated landscapes (Buchholtz et al. 2020, Lamb et al. 2020). Third, large carnivores

101 have the potential to affect community-level processes through top-down control on prey

102 abundance and thus trophic cascades (Hebblewhite et al. 2005, Hebblewhite and Merrill 2011,

103 Ripple et al. 2014). Consequently, understanding how movements of carnivores are affected by

104 connectivity and corridor design policies (Ford et al. 2020) is an important step towards better

105 management of ecosystem-level process (Terborgh et al. 1999).

106 The novel approaches to quantifying connectivity afforded through SSF-derived

107 simulations may support better land use decision making for carnivore conservation. Here, we

108 focused on assessing carnivore connectivity in a transboundary region of Banff National Park

109 (BNP), AB, Canada where transportation infrastructure, outdoor recreation, and urban areas

110 occupy much of the prime habitat in the valley bottoms of the mountainous landscape. We focus

111 on the movements of grizzly bears (Ursus arctos) and wolves (Canis lupus) because of their

112 management relevance, threatened status, and important ecological roles (e.g. Hebblewhite et al.

113 2005). We used 20 years of grizzly bear and wolf telemetry data to develop seasonal hidden 
114 Markov models and SSFs. We simulated animal paths from the movement models and SSFs to

115 assess changes in UDs and connectivity. Based on grizzly bear and wolf responses to human

116 activity in other studies (Whittington et al. 2005, Hebblewhite and Merrill 2008, Lamb et al.

117 2020), we expected grizzly bears and wolves to select linear features as efficient travel routes

118 while avoiding areas near towns and areas with high trail density. We expected avoidance to be

119 most pronounced and connectivity to be lowest during peak tourist visitation in summer. Finally,

120 we expected that connectivity around towns would decrease from current to future conditions

121 due to an expanded town footprint and increased recreational trail density (Gutzwiller et al.

122 2017). Building on the growing field of movement ecology, we provide a flexible approach to

123 generate movement-based estimates of connectivity that can be applied to other taxa and

124 systems.

126 Materials and Methods

\section{Study area}

128 The study area encompassed $17,450 \mathrm{~km}^{2}$ of the Canadian Rockies within and adjacent to BNP

$129\left(51.2^{\circ} \mathrm{N}, 115.5^{\circ} \mathrm{W}\right.$, Appendix S1: Figure S1). We defined the extent of the study area based on

130 movements of radio-collared wolves and grizzly bears monitored from 2000 to 2020. The study

131 area contained rugged topography, short summers and long cold winters. See Whittington et al.

132 (2019) for a description of vegetation and the predator-prey community.

133 The study area contained the tourist towns of Banff and Canmore and several hamlets

134 that occupied the centre of the Bow Valley. Linear features such as the Trans Canada highway, a

135 national railway, and secondary roads bisected the study area. Like many global protected areas

136 (Wittemyer et al. 2008), human activity within the study area increased steadily over the last 20 
137 years (Alberta Environment and Parks 2018), with the potential for increasing impacts on

138 wildlife connectivity (Gutzwiller et al. 2017). BNP currently receives over 4 million visitors per

139 year, mostly concentrated in summer. Most anthropogenic developments and recreational

140 activities were concentrated near roads within the Bow Valley. Backcountry areas in the

141 northeastern portion of the study area received minimal human use.

\section{Telemetry data}

143 Researchers fit wolves and grizzly bears with Global Positioning System (GPS) collars to

144 collect data from 2000 to 2020. Researchers captured and collared grizzly bears using a

145 combination of culvert traps and free-range darting and wolves using a net shot from a helicopter

146 under University and Federal government capture and Animal Care permits (see Appendix S1

147 for summary of permits). Researchers programmed most collars to collect GPS locations every

148 two hours. GPS collars had high fix rates with low habitat-induced fix-rate bias (Hebblewhite et

149 al. 2007). We obtained a large sample of locations from both front and backcountry areas (Figure

150 2, Appendix S1: Figures S1 - S3).

\section{Statistical analyses}

We used a three stage, individual-based modeling approach to quantify carnivore

153 responses to anthropogenic features and connectivity (Figure 1). Here, we provide an overview

154 of our methods and then provide additional details for each step of the analysis. First, we applied

155 hidden Markov models to animal movement data to predict slow versus fast movement states as

156 well as movement parameters and transition probabilities for both movement states. We

157 associated slow states with feeding or resting behaviour, and fast states with travelling

158 behaviour. Second, we integrated movement states into SSFs, such that each SSF contained

159 interactions between movement state, directional persistence, and movement rates. This enabled 
us to simulate state-specific movements directly from our SSF. We used results of the SSF to

161 assess responses to anthropogenic features. We also developed home-range scale resource

162 selection function (RSF) models to evaluate scale-dependence of SSF models for connectivity

163 evaluation. Third, we used the combination of hidden Markov models and SSFs with covariates

164 to simulate realistic individual-based movements. We simulated movement paths under three

165 landscape conditions reflecting reference, current, and future levels of anthropogenic

166 development. Reference represented a null model of potential habitat with no anthropogenic

167 development. We compared transect crossing rates and UDs from current and future conditions

168 to reference conditions to estimate connectivity and change in the amount of high-quality habitat

169 for each carnivore.

Movement model

171 We fit hidden Markov models to grizzly bear and wolf GPS step lengths and turn angles

172 so that we could incorporate movement behaviour into SSFs and to create biologically realistic

173 simulations of animal movement. We used functions from the moveHMM package version 1.7 to

174 fit hidden Markov models (Michelot et al. 2016). For each species and season, we fit two-state

175 movement models to reflect slow and fast movements, following previous studies of GPS

176 movement (Fryxell et al. 2008). We used the gamma distribution for step length and the circular

177 von Mises distribution for turn angles (Avgar et al. 2016). We included the cosine of hour as a

178 covariate to allow for diurnal variation in the frequency of slow and fast states. We predicted the

179 probability of being in a fast state for each GPS location, which we then incorporated into the

180 SSF below (Figure 1). We further used parameters from the movement models to simulate

181 movement states, step lengths, and turn angles in the path simulations below. 


\section{Step and resource selection: responses to development across scales}

We developed grizzly bear and wolf SSF and RSF to assess how anthropogenic development, topography, and land cover affected seasonal wolf and grizzly bear movement (Figure 1). One of the challenges of interpreting SSFs is that results can depend on sampling scale, i.e., time between locations (Mahoney et al. 2018). To ensure results of our SSF-based movement models were consistent with third-order within home range processes, we developed complementary RSF models for individual wolf and grizzly bears to evaluate potential scaledependence in SSF results.

The SSF models compared movement and environmental attributes of used steps to matched available locations (Avgar et al. 2016, Signer et al. 2019). We estimated each animal's movement parameters for step length and turn angle. We sampled from these movement parameters to generate random locations around each used location to sample availability. For each animal's step (strata $i$ ) we generated $J=10$ paired random locations. We extracted covariate vectors $\boldsymbol{x}_{i j}$ for each location and used conditional logistic regression to estimate covariate vector

$\boldsymbol{\beta}$.

$$
\operatorname{Pr}\left(y_{i j}=1 \mid \boldsymbol{x}_{i j}\right)=\pi_{i j}=\frac{\exp \left(\boldsymbol{\beta} \boldsymbol{x}_{i j}\right)}{\sum_{j=1}^{J} \exp \left(\boldsymbol{\beta} \boldsymbol{x}_{i j}\right)}
$$

We followed the modelling strategies outlined by Muff et al. (2020) for used-available SSF and RSF designs. We used the Poisson formulation of conditional logistic regression to fit the SSF and included random intercepts for each strata $i$. We accounted for individual animal variability in selection by including random coefficients for explanatory variables. We set weights for used locations to 1.0 and random locations to 1000 , and fixed the variance of the 
random intercept for strata to $10^{4}$. We used the $\mathrm{R}$ packages amt version 0.0.9 (Signer et al. 2019) to define available locations and glmmTMB version 1.0.1 (Brooks et al. 2017) to estimate the models. We visualized the effects of covariates on the relative probability of selection using relative selection strength $(\mathrm{RSS})$ where $\mathrm{RSS}=\exp (\boldsymbol{\beta} \boldsymbol{x})($ Avgar et al. 2017).

210 (Roever et al. 2014, Duchesne et al. 2015). We first predicted the probability of fast state for 211 each used location from the hidden Markov model (section 2.3.1 above, Figure 1). We applied 212 that predicted probability to all paired available locations. Our SSF then included interactions

213 between probability of fast state and the natural logarithm of step length and between probability

214 of fast state and the cosine of turn angle (Avgar et al. 2016). Thus, selection for step lengths

215 (speed) and turn angles (persistence) depended on movement state. The cosine of turn angle 216 reflected a measure of directional persistence with values ranging between -1.0 when animals

217 turned around to 1.0 when they continued in the same direction.

219 available locations within each individual animal's 95\% minimum convex polygon. We used

220 logistic regression to fit the RSF and included random intercepts for each animal. We accounted

221 for individual animal variability in selection by including random coefficients for explanatory

222 variables. We set weights for used locations to 1.0 and random locations to 1000, and fixed the

223 variance of the random intercept for strata to $10^{4}$. We used the R packages amt version 0.0 .9

224 (Signer et al. 2019) to define available locations and glmmTMB version 1.0.1 (Brooks et al.

225 2017) to estimate the models. We used the same explanatory variables for both SSF and RSF

226 models. We visually compared parameter estimates for the SSF and RSF models for consistency

227 in responses to anthropogenic development. 
The SSFs and RSFs included environmental and anthropogenic explanatory variables that were previously found to be important predictors of grizzly bear or wolf resource selection in the

230 Canadian Rockies (Nielsen et al. 2006, Hebblewhite and Merrill 2008, Rogala et al. 2011). To

231 minimize collinearity, we removed explanatory variables that had Pearson correlation

232 coefficients $>0.6$ and variance inflation factors $>2.0$. When two variables were highly

233 correlated, we selected the covariate based on biological relevance and predictive power that we

234 assessed with univariate plots. All models contained the same 17 environmental and

235 anthropogenic covariates. Environmental covariates included five land cover classes, elevation

$236(\mathrm{~m})$, the negative cosine of aspect such that south $=1.0$ and north $=-1.0$, slope (degrees),

237 proximity to forest edge $(\mathrm{km})$, proximity to large patch of vegetated habitat greater than $9 \mathrm{~km}^{2}$

238 (Proctor et al. 2015), and an indicator variable for whether the area had burned since 1960. See

239 Appendix S1: Table S2 for details.

240 Covariates for anthropogenic development included proximity to towns (km), proximity

241 to campgrounds $(\mathrm{km})$, density of formal trails $\left(\mathrm{km} / \mathrm{km}^{2}, 500 \mathrm{~m}\right.$ radius $)$, and indicator variables

242 for whether the animal was on or off trails and the railway. We classified distance to town based

243 on a digitized aerial photograph of buildings and developed areas within towns. We excluded

244 green spaces and golf courses from the town footprint. We predicted that carnivores would select

245 for trails and the railway as travel routes. We predicted that carnivores would avoid areas near

246 towns, campgrounds, and areas of high trail density, especially in summer during peak visitation

247 (Rogala et al. 2011). We lacked direct measures of human activity so we included an interaction

248 between trail density and the natural logarithm of distance to paved road $(\mathrm{km})$. We assumed that

249 trail use would be highest near trail heads along paved roads (Rogala et al. 2011, Zhai et al.

250 2018). We included an interaction between proximity to town and time of day (cosine of hour) 
251 because we expected stronger avoidance of towns during the day compared to the night

252 (Hebblewhite and Merrill 2008). We applied a decay term $\left(1-\exp ^{-10 * \text { distance }}\right)$ to the distance

253 covariates so that the influence of these features had an asymptote near $500 \mathrm{~m}$ (Shepherd and

254 Whittington 2006, Rogala et al. 2011). We scaled all other continuous covariates by their mean

255 and standard deviation to improve model convergence.

Animal resource selection and responses to anthropogenic development can vary

257 seasonally. Thus, we defined four seasons and created separate SSF models for each species and

258 season. We defined seasons based on animal movement, plant phenology, and human visitation

259 rates to BNP. We classified Spring as May and June which included plant emergence, ungulate

260 parturition, grizzly bear mating, wolf denning, and moderate levels of human activity; Summer as

261 July and August during the height of berry season and peak visitation; and Fall as September and

262 October when plants have senesced and the study area received moderate levels of visitation, and

263 Winter as November through April for wolves with lower levels of visitation in backcountry

264 areas and high levels of visitation near ski hills and towns.

265 Connectivity and habitat degradation

266 We simulated individual-based carnivore movements from our SSFs across three

267 landscape scenarios, from which we estimated connectivity and changes in the amount of high

268 quality habitat (Figure 1). We used a combination of the hidden Markov models and SSFs to

269 simulate carnivore movements throughout the study area (Figure 1, Appendix S1: Figure 1). We

270 simulated 200,000 paths within the $17,000 \mathrm{~km}^{2}$ study are for each species, season, and landscape

271 scenario. We selected random start locations and initial directions of travel. For each path, we

272 sampled $s=720$ movement states (steps, $s$ ) with two-hour fix interval across $t=60$ days from the

273 hidden Markov models. We chose 60 days to match the duration of spring, summer, and fall 
274 seasons used in the step selection analyses. For each step, we sampled $n=20$ step lengths and

275 turn angles from the state-specific movement parameters. We extracted environmental attributes

276 of the proposed locations and used the combination of environmental attributes and movement

277 parameters to calculate probability of use conditional on the 20 sample locations (equation 1).

278 We probabilistically selected one of the proposed locations and continued to the next step. We

279 repeated this process for all steps in the path.

280 The study occurred in a rugged environment where steep, rocky mountain ranges can

281 influence animal movements. We therefore defined unavailable habitat as barren landscapes with

282 slopes $\geq 35$ degrees, which were used by grizzly bears and wolves 1.9 and $0.2 \%$ of the time,

283 respectively. We also classified towns and developed areas as unavailable habitat. To create

284 realistic movement paths, we reduced the probability of simulated steps jumping across

285 mountain ranges and towns by sampling four equidistant locations along proposed steps. We

286 rejected steps if any of those locations occurred in the unavailable habitat. We minimized

287 boundary effects on spatial predictions of use by terminating paths when $>40 \%$ of the proposed

288 steps occurred outside the study area and by setting the study area boundary $>30 \mathrm{~km}$ from the

289 towns of Banff and Canmore. Finally, start locations could occur in poor quality habitat, so we

290 removed the first twelve ( $t=1$ day) steps from each path while paths oriented to higher quality

291 habitat.

292 We simulated animal movements for three scenarios with varying levels of anthropogenic

293 development: reference, current, and future. First, we removed the effect of towns, roads, and the

294 railway from SSFs when simulating paths under reference conditions, which we used as a null

295 model of movement (Heinemeyer et al. 2019, Brennan et al. 2020). In reality, First Nations have

296 occupied the study area for over 11,000 years (Langemann 2011) and the reference condition 
underestimated the historical effects of human activity. Second, we simulated animal movements

298 under current conditions from which we developed our SSFs. Finally, we simulated animal

299 movements under one future scenario with expanded development and trail density. We

300 modified the town of Canmore's developed footprint to reflect residential and business

301 development proposals in the 2020 Smith Creek and Three Sisters area structure plans

302 (QuantumPlace Developments Ltd. 2020b, a). We excluded green spaces and golf courses from

303 the developed footprint given that carnivores can use these areas for movement. The developed

304 footprint for the town of Banff is legally fixed under the National Parks Act and is not expected

305 to increase. However, like many mountain towns, the creation and intensity of use on informal

306 trails has increased near Banff and Canmore over the last ten years. We, thus added an inventory

307 of informal trails to the existing formal trail network and updated metrics of trail density.

308 Increased use of existing and new recreational trails has the potential to reduce wildlife

309 connectivity (Gutzwiller et al. 2017). We simulated animal movements with the updated town

310 and trail layers to estimate future connectivity.

311 To calculate connectivity, we created digital, cross-valley transects through the towns of

312 Banff and Canmore (Figure 2, Figure 3). We aligned transects so that they crossed the narrowest

313 movement corridors under current condition, where the combination of rugged topography and

314 development created pinch points to movement. We counted both the number of simulated paths

315 and individual steps that crossed transects on the north and south sides of the valley. We used

316 number of unique paths that crossed the transects as our metric of connectivity to reflect the

317 population level value of corridors. We calculated connectivity as $100 * n_{\text {cross }} / n_{\text {reference, where }}$

$318 n_{\text {cross }}$ was the number of unique paths that crossed in current or future conditions and $n_{\text {reference }}$ was 
319 the number of unique paths that crossed under reference conditions with no anthropogenic

320 development. We evaluated how connectivity changed with species, seasons, and time period.

321 Finally, we examined the effects of anthropogenic development on the amount of high

322 quality habitat available to carnivores. We calculated UDs as the number of simulated locations

323 that occurred within each $210 \times 210 \mathrm{~m}^{2}$ grid cell and then divided the tallies by the number of

324 total simulated locations (Signer et al. 2017). We classified reference UDs into three equal area

325 bins representing low, medium, and high quality habitat. We applied the same break points and

326 habitat classifications to UDs from the current and future scenarios. We then calculated changes

327 in the amount of high quality habitat. We focussed our analysis within a five km radius of the

328 Trans Canada Highway between Banff and Canmore $\left(366 \mathrm{~km}^{2}\right)$. The five $\mathrm{km}$ radius represented

329 the 0.99 and 0.95 quantiles of grizzly bear and wolf step lengths, respectively, and the focal

330 study approximately covered the peak to peak width of the Bow Valley. We calculated the

331 proportion of high quality habitat degraded due to anthropogenic development relative to

332 reference conditions (Heinemeyer et al. 2019). For example, our calculation of habitat

333 degradation under current conditions was (AreaHigh Reference $_{-}$-AreaHigh Current $_{\text {t }}$ /TotalArea,

334 whereby AreaHigh represented the area of high quality habitat and TotalArea, represented the

335 total area of the focal study. Our metric of habitat degradation thus accounted for both decreased

336 UDs near anthropogenic developments and concurrent increased UDs as simulated animals spent

337 more time in less developed portions of the landscape. We visually evaluated how habitat

338 degradation varied with species, seasons, and time period. 


\section{Results}

\section{Movement state}

342 We analysed GPS data from 34 grizzly bears (19 females, 15 males, 72,217 locations) and 33

343 wolves (13 females, 20 males, 84,434 locations; Appendix S1: Figure S1 - S3). Hidden Markov

344 models revealed that grizzly bears and wolves spent a similar proportion of time in their fast state

345 ( $p=0.64$ and 0.60 respectively). Grizzly bears and wolves had the same median step lengths for

346 slow steps $(16 \mathrm{~m})$ (Appendix S2: Table S1). Wolf fast steps (median $=1270 \mathrm{~m})$ were on average

3472.5 times longer than grizzly bear fast steps (median $=496 \mathrm{~m})$. Grizzly bears had a much

348 stronger diurnal cycle of movement states than wolves (Figure 4). Grizzly bears increased their

349 proportion of time in slow states at night. Wolves had a weaker and sometimes opposite diurnal

350 cycle. Wolves increased the proportion of time in slow states at night during fall and winter only.

351 Wolves increased the proportion of time in fast states at night during spring and summer, which

352 coincided with the longest days of the year.

\section{Step and resource selection: responses to development across scales}

As expected, we found that wolves and grizzly bears generally avoided areas with high

355 levels of human activity in all seasons (Figure 5, Figure 6, Supplementary Table S2). Both

356 species strongly avoided areas near towns (median $\beta=1.11$, range from 0.44 to 2.08 ) and $95 \%$

357 CI's excluded zero on 6 of the 7 models (Figure 4). Grizzly bear and wolf responses to areas near 358 town changed slightly at night, though the effect size was small compared to avoidance of towns

359 in general. Parameter estimates for distance to town were $>10$ times larger than parameter

360 estimates for the distance to town by night time interaction (Figure 5, Figure 6). Grizzly bear

361 avoidance of towns diminished at night in all seasons (e.g., summer $\beta=-0.05, \mathrm{SE}=0.01$ ). Wolf

362 response to towns diminished at night during winter $(\beta=-0.05, \mathrm{SE}=0.01)$, but strengthened 
363 during summer $(\beta=-0.05, \mathrm{SE}=0.01)$, and fall $(\beta=-0.05, \mathrm{SE}=0.01)$. Grizzly bears and wolves

364 avoided areas with high trail density near paved roads (median $\beta=-0.93$, range from -1.92 to

365 0.151) with all but one estimate being less than zero and five out of seven models with 95\% CI's

366 that excluded zero. Carnivore responses to trail density tapered with distance to paved roads

367 (Figure 6). Wolves avoided areas near vehicle accessible campgrounds during summer when

368 campgrounds were most active (e.g., summer $\beta=1.00, \mathrm{SE}=0.41$ ). Grizzly bears avoided areas

369 near campgrounds during the fall but not during the summer berry season nor in the spring.

370 Grizzly bears and wolves weakly selected trails during all seasons with the strongest selection for

371 grizzly bears in summer and for wolves in winter. Grizzly bears selected the railway during the

372 spring and fall and avoided the railway during the summer berry season. Wolves strongly

373 selected the railway during winter and weakly selected the railway at other times of the year.

374 RSF models had similar parameter estimates compared to SSF models confirming

375 minimal scale-dependence of our SSF results (Figure 5, Appendix S2: Table S3, Table S4). Most

376 (84\%) of the SSF and RSF anthropogenic parameters had the same positive or negative sign.

377 Most sign differences occurred for parameters with 95\% CI's that overlapped zero. From a

378 management perspective, the biggest difference in parameter estimates was that the grizzly bear

379 fall SSF suggested weak avoidance of areas near town $(\beta=0.44, \mathrm{SE}=0.26)$, whereas the RSF

380 suggested grizzly bears selected areas near town $(\beta=-0.81, \mathrm{SE}=0.13)$. Otherwise, all other

381 parameter estimates for distance to town were positive. Overall, the RSF results supported the

382 scale-independence of our SSF results regarding carnivore avoidance of areas near towns and

383 areas with high trail density. 


\section{Connectivity and habitat degradation}

Simulated paths under reference, current, and future land use scenarios had similar movement attributes compared observed paths (e.g., Figure 2, Figure 3). Both simulated and observed paths contained series of short steps with high turn angles interspersed with long distance movements with strong directional persistence. Under reference conditions, simulated paths were concentrated in the valley bottoms and used areas within the current footprint of towns. The combination of towns and rugged topography constrained the movements of both observed and simulated paths under current and future scenarios. This resulted in UDs with low

392 frequencies of occurrence near towns and areas of high trail density and high UDs in more 393 remote areas of the Bow Valley (Appendix S1: Figures S4 - S5).

Grizzly bear and wolf connectivity across digital transects on the north and south sides of

395 Banff and Canmore ranged between 7 and $45 \%$ under current conditions with mean values of

$39621 \%$ for grizzly bears and $25 \%$ for wolves (Figure 7). Grizzly bear and wolf connectivity further

397 decreased from current to future conditions an average of $6 \%$ and 5\% respectively (range $=0$ to

398 13\%). Connectivity for grizzly bears and wolves was highest in the spring. Grizzly bear

399 connectivity was lowest in the summer, whereas wolf connectivity was lowest in the fall and

400 winter. Grizzly bear connectivity was on average higher along the northern transects compared to

401 the southern transects. Wolf connectivity was highest on the northern side of Banff and lowest on

402 the southern side of Canmore.

404 including areas near Banff and Canmore under reference conditions (Figure 2, Figure 3,

405 Supplementary Figures S4 and S5). UDs under current and future conditions showed a

406 cumulative decrease in use in and around the towns. The decrease in use near towns was offset 
407 by increased use in more remote areas of the valley. The proportion of high quality habitat

408 degraded due to anthropogenic development increased from current (mean $=0.145$, range $=$

4090.088 to 0.183 ) to future conditions (mean $=0.164$, range $=0.126$ to 0.198 ; Figure 8 ). Habitat

410 degradation was highest in summer and lowest in the spring and fall for grizzly bears. Habitat

411 degradation was high for wolves in the summer, fall, and winter, and lowest in the spring.

\section{Discussion}

414 Our study used a combination of hidden Markov models and SSFs to estimate utilizations,

415 connectivity, and changes in the amount of high quality due to current and future estimates of

416 anthropogenic development. Our approach assessed the cumulative effects of multiple

417 anthropogenic features on carnivore movements and connectivity around the towns of Banff and

418 Canmore, Alberta, which averaged 23\% relative to reference conditions. A scenario of future

419 development and trail expansion would further reduce connectivity by an average of 5 to $6 \%$. By

420 using empirically-derived parameters in an individual-based simulation, our approach offers a

421 tangible response variable for scientists to convey to land use decision makers. For example,

422 rather than translating how 'current density' may change under different scenarios, we are able to

423 estimate a percent change in the number of animals moving through a corridor under predicted

424 land use scenarios.

425 The main advantages of our approach are as follows: 1) simulated movements directly

426 from an SSF with multiple behavioural states helped create realistic movement paths where

427 movement decisions were based on resource selection parameters; 2) our approach avoided

428 transforming SSFs into resistance surfaces used for circuit-theory and cost-distance analyses,

429 which have an weak theoretical link to movement ecology; and 3) estimates for changes in UDs 
430 and connectivity have a simpler interpretation and a tighter link to movement probabilities

431 compared to least-cost and circuit theory based estimates of connectivity. We chose to estimate

432 connectivity by comparing transect crossing rates of simulated paths through narrow movement

433 corridors, which in our study area are of conservation concern. Our approach could easily be

434 expanded to examine the frequency with which paths travel between habitat patches (e.g. Suraci

435 et al. 2020), between summer and winter ranges (Merkle et al. 2019), across highways with

436 increased mortality risk (e.g. Quaglietta et al. 2019), or through other areas of conservation

437 concern.

438 Our study supports the growing body of research showing that wildife avoid some forms

439 of human activity (e.g. Gaynor et al. 2018, Tucker et al. 2018, Nickel et al. 2020), which can lead

440 to habitat fragmentation and reductions in connectivity (e.g. Bischof et al. 2017, Hilty et al.

4412020 , Suraci et al. 2020). Given the global growth in human activity adjacent to protected areas

442 (Wittemyer et al. 2008), and concurrent impacts of growing recreation in these landscapes

443 (Gutzwiller et al. 2017), our approach and results emphasize the importance of cumulative

444 effects assessment in regions surrounding parks and protected areas.

445 Numerous studies have found that grizzly bears (Chetkiewicz and Boyce 2009, Morales-

446 González et al. 2020) and wolves (Hebblewhite and Merrill 2008, Rogala et al. 2011, Anton et

447 al. 2020) avoid human activity, which can contribute to the fragmentation of populations

448 (Proctor et al. 2012, Bischof et al. 2017). However, few studies have compared the behaviour of

449 the two species. Wolves in our study exhibited stronger avoidance of towns, similar responses to

450 trails, and weaker selection for the railway compared to grizzly bears. Grizzly bears and wolves

451 had higher connectivity estimates in spring, which coincided with lower levels of human activity

452 and a concentration of food resources and wolf movements to and from den sites in valley 
453 bottoms. Interestingly, wolf connectivity estimates were slightly higher than grizzly bear

454 connectivity estimates. One reason for this disconnect could be that wolves had faster speeds of

455 travel, fewer steps were required to traverse corridors, and perhaps simulated steps could more

456 easily jump across towns. Parameterizing models using path selection functions or collecting

457 finer resolution GPS data could help reduce the probability of paths crossing inhospitable

458 features. For instance, path selection functions can sometimes produced stronger regression

459 coefficients and better connectivity models compared to SSFs (Zeller et al. 2015, Zeller et al.

460 2018). Further, we did not assess how individual variability in animal responses to anthropogenic

461 development affected connectivity (Muff et al. 2020). Simulating movements from random

462 coefficients could highlight estimates of connectivity for both wary and habituated animals and

463 could help identify areas likely to have high levels of human wildlife conflict (Buchholtz et al.

464 2020, Lamb et al. 2020).

465 Two limitations of our study bear further consideration for similar work in the future.

466 First, we lacked direct measurements of human activity on trail networks (Alberta Environment

467 and Parks 2018). Because carnivores typically avoid encounters with people rather than linear

468 features, our lack of high resolution trail use data likely reduced the effect size and precision of

469 parameter estimates for trail density. Estimates of recreational activity could be improved by

470 directly tracking individual movements (Heinemeyer et al. 2019), inferring activity from mobile

471 device data (Corradini et al. 2021), or modelling spatial and temporal trends in trail use (Ladle et

472 al. 2019). Better estimates of recreational activity would improve our understanding of how

473 recreational activity affects wildlife movement and our ability to manage human-wildlife

474 coexistence (Rogala et al. 2011, Naidoo and Burton 2020). Second, our data consisted of animal

475 movements within established home ranges rather than dispersal or nomadic movements that are 
476 important for landscape-scale connectivity (Fattebert et al. 2015). Other studies suggest animals

477 select different resources and may have increased tolerance for human activity when dispersing

478 when compared to movement within the home range. For instance, resistance models for Iberian

479 lynx under-estimated connectivity when they were developed using GPS data from within home

480 range movements (Blazquez-Cabrera et al. 2016). Further development and evaluation of

481 connectivity models using dispersal data would be important when evaluating connectivity

482 between isolated populations (Zeller et al. 2018).

Restoration actions, such as removal of human footprint, managing or consolidating

484 recreational activity, and trail closures have potential to improve habitat quality and connectivity.

485 Wildlife increased their use of corridors and degraded habitat following reductions in human

486 activity, both in our ecosystem (Duke et al. 2001, Shepherd and Whittington 2006, Whittington

487 et al. 2019) and around the world (Ngoprasert et al. 2017). For example, early work in our study

488 area demonstrated positive wildlife connectivity consequences of removing recreational footprint

489 in the Cascade wildlife corridor on the north side of the Banff town site (Duke et al. 2001), and

490 positive effects of a temporal road closure on wildlife habitat quality (Whittington et al. 2019).

491 Our approach for simulating animal movements and assessing connectivity could be applied to

492 assess the effects of potential restoration actions on fine-scale connectivity (Wang et al. 2014,

493 Mariela et al. 2020, Suraci et al. 2020). Simulations and restoration actions could focus on

494 highway mitigations (Quaglietta et al. 2019), reductions in trail density, permanent closures,

495 seasonal closures, or temporal closures (Whittington et al. 2019). In the face of global increases

496 in human activity, especially surrounding parks and protected areas (Wittemyer et al. 2008),

497 proactive habitat protection and restoration actions will be required to maintain habitat quality

498 and connectivity for wide ranging wildlife (Hilty et al. 2020). 


\section{Acknowledgements}

501 Parks Canada, the University of Montana, the University of Alberta, and Canadian Pacific

502 Railway contributed to the collection of grizzly bear and wolf GPS data. MH acknowledges

503 funding from NSF LTREB grant \# 1556248. We thank J. Merkle for provided advice on step

504 selection analyses and B. Hunt, A. Forshner, and S. Williams for their insights on earlier versions

505 of the manuscript. Parks Canada provided financial support for data collection and analysis.

506

507 Supporting Information

508 Appendix S1. Maps of study area, observed GPS locations, and predicted utilization distributions

509 from step selection function models.

510 Appendix S2: Tables of parameter estimates from movement models, step selection functions,

511 and resource selection functions.

\section{Data availability}

514 We will submit GPS movement data, scripts to fit hidden Markov models, step selection

515 functions, and simulations under current conditions to Data Dryad.

\section{$517 \quad$ Literature cited}

518 Abrahms, B., S. C. Sawyer, N. R. Jordan, J. W. McNutt, A. M. Wilson, and J. S. Brashares. of Applied Ecology 54:412-422. 
Alberta Environment and Parks. 2018. Human-wildlife coexistence: recommendations for improving human-wildlife coexistence in the Bow Valley.

Anton, C. B., D. W. Smith, J. P. Suraci, D. R. Stahler, T. P. Duane, and C. C. Wilmers. 2020. National Park. Ecosphere 11:e03164.

Avgar, T., S. R. Lele, J. L. Keim, and M. S. Boyce. 2017. Relative selection strength: quantifying effect size in habitat- and step-selection inference. Ecology and Evolution 7:5322-5330.

Avgar, T., J. R. Potts, M. A. Lewis, and M. S. Boyce. 2016. Integrated step selection analysis: bridging the gap between resource selection and animal movement. Methods in Ecology

Benz, R. A., M. S. Boyce, H. Thurfjell, D. G. Paton, M. Musiani, C. F. Dormann, and S. Ciuti. 2016. Dispersal ecology informs design of large-scale wildlife corridors. PLoS ONE

Bischof, R., S. M. J. G. Steyaert, and J. Kindberg. 2017. Caught in the mesh: roads and their 11:e0162989. network-scale impediment to animal movement. Ecography 40:1369-1380. 
Brooks, M. E., K. Kristensen, K. J. van Benthem, A. Magnusson, C. W. Berg, A. Nielsen, H. J. among packages for zero-inflated generalized linear mixed modeling. The $\mathrm{R}$ journal 9:378-400.

Buchholtz, E. K., A. Stronza, A. Songhurst, G. McCulloch, and L. A. Fitzgerald. 2020. Using landscape connectivity to predict human-wildlife conflict. Biological Conservation

Buderman, F. E., M. B. Hooten, J. S. Ivan, and T. M. Shenk. 2018. Large-scale movement 248: 108677 .

Calabrese, J. M., and W. F. Fagan. 2004. A comparison-shopper's guide to connectivity metrics. Frontiers in Ecology and the Environment 2:529-536.

Chetkiewicz, C. L. B., and M. S. Boyce. 2009. Use of resource selection functions to identify conservation corridors. Journal of Applied Ecology 46:1036-1047.

Duchesne, T., D. Fortin, and L.-P. Rivest. 2015. Equivalence between step selection functions and biased correlated random walks for statistical inference on animal movement. PLoS ONE 10:e0122947. carnivore corridor in Banff National Park. Pages 261-275 in D. Maehr, R. F. Noss, and J. Larkin, editors. Large mammal restoration: ecological and social challenges in the 21 st century. Island Press, Washington, DC. 
Fattebert, J., H. S. Robinson, G. Balme, R. Slotow, and L. Hunter. 2015. Structural habitat predicts functional dispersal habitat of a large carnivore: how leopards change spots. Ecological Applications 25:1911-1921.

Ford, A. T., E. J. Sunter, C. Fauvelle, J. L. Bradshaw, B. Ford, J. Hutchen, N. Phillipow, and K. J. Teichman. 2020. Effective corridor width: linking the spatial ecology of wildlife with land use policy. European Journal of Wildlife Research 66:69.

Fortin, D., H. L. Beyer, M. S. Boyce, D. W. Smith, T. Duchesne, and J. S. Mao. 2005. Wolves influence elk movements: behavior shapes a trophic cascade in Yellowstone National Park. Ecology 86:1320-1330.

Fryxell, J. M., M. Hazell, L. Börger, B. D. Dalziel, D. T. Haydon, J. M. Morales, T. McIntosh,

Fullman, T. J., R. R. Wilson, K. Joly, D. D. Gustine, P. Leonard, and W. M. Loya. 2021. Mapping potential effects of proposed roads on migratory connectivity for a highly and R. C. Rosatte. 2008. Multiple movement modes by large herbivores at multiple spatiotemporal scales. Proceedings of the National Academy of Sciences 105:19114-

Gutzwiller, K. J., A. L. D'Antonio, and C. A. Monz. 2017. Wildland recreation disturbance: broad-scale spatial analysis and management. Frontiers in Ecology and the Environment 15:517-524.

Hebblewhite, M. 2005. Predation by wolves interacts with the North Pacific Oscillation (NPO) on a western North American elk population. Journal of Animal Ecology 74:226-233. 
Hebblewhite, M., and E. Merrill. 2008. Modelling wildlife-human relationships for social species with mixed-effects resource selection models. Journal of Applied Ecology 45:834-844.

Hebblewhite, M., and E. H. Merrill. 2011. Demographic balancing of migrant and resident elk in a parially migratory population through forage-predation tradeoffs. Oikos 120:18601870.

Hebblewhite, M., M. Percy, and E. H. Merrill. 2007. Are all global positioning system collars created equal? Correcting habitat-induced bias using three brands in the Central Canadian Rockies. Journal of Wildlife Management 71:2026-2033. Bayley, and P. C. Paquet. 2005. Human activity mediates a trophic cascade caused by wolves. Ecology 76:2135-2144.

604 Hilty, J., G. Worboys, A. Keeley, S. Woodley, B. Lausche, H. Locke, M. Carr, I. Pulsford, J. Pittock, and J. W. White. 2020. Guidelines for conserving connectivity through ecological networks and corridors. Gland, Switzerland: IUCN-WCPA. mechanistic selection functions. Spatial Statistics 37:100406.

609 Jayadevan, A., R. Nayak, K. K. Karanth, J. Krishnaswamy, R. DeFries, K. U. Karanth, and S. Vaidyanathan. 2020. Navigating paved paradise: Evaluating landscape permeability to 
movement for large mammals in two conservation priority landscapes in India. Biological Conservation 247:108613.

613 Ladle, A., T. Avgar, M. Wheatley, G. B. Stenhouse, S. E. Nielsen, and M. S. Boyce. 2019.

614 Grizzly bear response to spatio-temporal variability in human recreational activity.

$615 \quad$ Journal of Applied Ecology 56:375-386.

616 Lamb, C. T., A. T. Ford, B. N. McLellan, M. F. Proctor, G. Mowat, L. Ciarniello, S. E. Nielsen, and S. Boutin. 2020. The ecology of human-carnivore coexistence. Proceedings of the

619 Langemann, E. G. 2011. Archaeology in the Rocky Mountain National Parks: uncovering an 11,000-year-long story. A Century of Parks Canada, 1911-2011:303-332.

Mahoney, P. J., G. E. Liston, S. LaPoint, E. Gurarie, B. Mangipane, A. G. Wells, T. J. Brinkman, J. U. H. Eitel, M. Hebblewhite, A. W. Nolin, N. Boelman, and L. R. Prugh. 2018. Navigating snowscapes: scale-dependent responses of mountain sheep to snowpack

Mariela, G., C. Laura, and J. L. Belant. 2020. Planning for carnivore recolonization by mapping properties. Ecological Applications 28:1715-1729. Wilson. 2017. Multi-species genetic connectivity in a terrestrial habitat network.

630 Merkle, J. A., H. Sawyer, K. L. Monteith, S. P. H. Dwinnell, G. L. Fralick, and M. J. Kauffman. 2019. Spatial memory shapes migration and its benefits: evidence from a large herbivore. Ecology Letters 22:1797-1805. 
633 Meurant, M., A. Gonzalez, A. Doxa, and C. H. Albert. 2018. Selecting surrogate species for

634 connectivity conservation. Biological Conservation 227:326-334.

635 Michelot, T., R. Langrock, and T. A. Patterson. 2016. moveHMM: an R package for the

636 statistical modelling of animal movement data using hidden Markov models. Methods in

$637 \quad$ Ecology and Evolution 7:1308-1315.

638 Morales-González, A., H. Ruiz-Villar, A. Ordiz, and V. Penteriani. 2020. Large carnivores living alongside humans: Brown bears in human-modified landscapes. Global Ecology and Conservation 22:e0937.

641 Muff, S., J. Signer, and J. Fieberg. 2020. Accounting for individual-specific variation in habitatselection studies: Efficient estimation of mixed-effects models using Bayesian or frequentist computation. Journal of Animal Ecology 89:80-92.

644 Naidoo, R., and A. C. Burton. 2020. Relative effects of recreational activities on a temperate terrestrial wildlife assemblage. Conservation Science and Practice 2:e271.

646 Ngoprasert, D., A. J. Lynam, and G. A. Gale. 2017. Effects of temporary closure of a national park on leopard movement and behaviour in tropical Asia. Mammalian Biology 82:6573.

Nickel, B. A., J. P. Suraci, M. L. Allen, and C. C. Wilmers. 2020. Human presence and human

652 Nielsen, S. E., G. B. Stenhouse, and M. S. Boyce. 2006. A habitat-based framework for grizzly 
654 Palmer, S. C. F., A. Coulon, and J. M. J. Travis. 2011. Introducing a 'stochastic movement simulator' for estimating habitat connectivity. Methods in Ecology and Evolution 2:258268.

Panzacchi, M., B. Van Moorter, O. Strand, M. Saerens, I. Kivimäki, C. C. St. Clair, I. Herfindal, and L. Boitani. 2016. Predicting the continuum between corridors and barriers to animal movements using step selection functions and randomized shortest paths. Journal of Animal Ecology 85:32-42.

Proctor, M. F., D. Paetkau, B. N. McLellan, G. B. Stenhouse, K. C. Kendall, R. D. Mace, W. F.

Quaglietta, L., and M. Porto. 2019. SiMRiv: an R package for mechanistic simulation of grizzly bears in western Canada and the northern United States. Wildlife Monographs

QuantumPlace Developments Ltd. 2020a. Smith Creek area structure plan, July 2020.

674 QuantumPlace Developments Ltd. 2020b. Three Sisters area structure plan, July 2020.

675 Ray, J., K. H. Redford, R. Steneck, and J. Berger. 2013. Large carnivores and the conservation of biodiversity. Island Press. 
Ripple, W. J., J. A. Estes, R. L. Beschta, C. C. Wilmers, E. G. Ritchie, M. Hebblewhite, J. Berger, B. Elmhagen, M. Letnic, M. P. Nelson, O. J. Schmitz, D. W. Smith, A. D. Wallach, and A. J. Wirsing. 2014. Status and ecological effects of the world's largest carnivores. Science 343.

Roever, C. L., H. L. Beyer, M. J. Chase, and R. J. van Aarde. 2014. The pitfalls of ignoring behaviour when quantifying habitat selection. Diversity and Distributions 20:322-333.

Rogala, J. T., M. Hebblewhite, J. Whittington, C. A. White, J. Coleshill, and M. Musiani. 2011. Human activity differentially redistributes large mammals in the Canadian Rockies National Parks. Ecology and Society 16:16.

Shepherd, B., and J. Whittington. 2006. Response of wolves in winter to wildlife corridor restoration and human use management. Ecology and Society 11:1.

Signer, J., J. Fieberg, and T. Avgar. 2017. Estimating utilization distributions from fitted stepselection functions. Ecosphere 8:e01771.

Signer, J., J. Fieberg, and T. Avgar. 2019. Animal movement tools (amt): R package for managing tracking data and conducting habitat selection analyses. Ecology and Evolution 9:880-890.

Suraci, J. P., L. G. Frank, A. Oriol-Cotterill, S. Ekwanga, T. M. Williams, and C. C. Wilmers. 2019. Behavior-specific habitat selection by African lions may promote their persistence in a human-dominated landscape. Ecology 100:e02644.

Suraci, J. P., B. A. Nickel, and C. C. Wilmers. 2020. Fine-scale movement decisions by a large carnivore inform conservation planning in human-dominated landscapes. Landscape Ecology 35:1635-1649. 
Terborgh, J., J. A. Estes, P. Paquet, K. Ralls, D. Boyd-Herger, B. J. Miller, and R. F. Noss. 1999.

The role of top carnivores in regulating terrestrial ecosystems. Pages 39-64 in M. E. Soulé and J. Terborgh, editors. Continental Conservation: Scientific Foundations of Regional Reserve Networks. The Wildlands Project. Island Pres, Washington, D.C. 
Zwijacz-Kozica, and T. Mueller. 2018. Moving in the Anthropocene: Global reductions in terrestrial mammalian movements. Science 359:466-469.

723 Wang, F., W. J. McShea, D. Wang, S. Li, Q. Zhao, H. Wang, and Z. Lu. 2014. Evaluating landscape options for corridor restoration between giant panda reserves. PLoS ONE

Whittington, J., P. Low, and B. Hunt. 2019. Temporal road closures improve habitat quality for wildlife. Scientific reports 9:3772.

Whittington, J., C. C. St. Clair, and G. Mercer. 2005. Spatial responses of wolves to roads and trails in mountain valleys. Ecological Applications 15:543-553.

Wittemyer, G., P. Elsen, W. T. Bean, A. C. O. Burton, and J. S. Brashares. 2008. Accelerated human population growth at protected area edges. Science 321:123-126. and path selection functions for estimating resistance to movement: pumas as a case study. Landscape Ecology:1-17. 2018. Are all data types and connectivity models created equal? Validating common connectivity in a developing landscape. Land 9:233. 
bioRxiv preprint doi: https://doi.org/10.1101/2021.02.24.432739; this version posted February 25, 2021. The copyright holder for this preprint

(which was not certified by peer review) is the author/funder, who has granted bioRxiv a license to display the preprint in perpetuity. It is made available under aCC-BY-NC-ND 4.0 International license.

743 Zhai, Y., P. Korça Baran, and C. Wu. 2018. Can trail spatial attributes predict trail use level in

744 urban forest park? An examination integrating GPS data and space syntax theory. Urban

$745 \quad$ Forestry \& Urban Greening 29:171-182.

746 


\section{List of Figures}

748 Figure 1 . Workflow to assess connectivity and change in habitat quality using hidden Markov

749 models, SSFs, and RSFs. We classified movement behaviors into slow and fast states and then

750 used those states in SSF models and in path simulations. Simulated points can be used to

751 estimate UDs and changes in habitat quality. Connectivity can be measured by comparing

752 movement rates through corridors, across transects, or between patches relative to a reference

753 model of movement with no anthropogenic development.

754

755 Figure 2. Illustration of our connectivity modeling approach in Figure 1 for one species (wolf)

756 and one season (summer) showing the distribution of observed wolf paths around the town of

757 Banff, a random sample of simulated paths under three land use scenarios, and expected

758 utilization distribution. We used hidden Markov models and SSFs to simulate 200,000

759 movement paths across a two-month window. We tallied the number of paths that crossed the

760 valley wide transect and calculated connectivity as the ratio of current to reference and future to

761 reference crossing frequencies. We further quantified habitat degradation as changes in the area

762 of high quality habitat relative to reference conditions.

763

764 Figure 3. Illustration of our connectivity modeling approach in Figure 1 for one species (wolf)

765 and one season (summer) showing the distribution of observed wolf paths around the town of

766 Canmore, a random sample of simulated paths under three land use scenarios, and expected

767 utilization distribution. 
769 Figure 4. Grizzly bear and wolf movement state probabilities (slow versus fast movements) and

$77095 \%$ CI's depended on time of day. Movement states were predicted from hidden Markov

771 models developed from GPS locations. Slow and fast states are interpreted to represent feeding-

772 resting and travel behaviours, respectively.

773

774 Figure 5. Human use related parameter estimates and 95\% CI's from grizzly bear and wolf SSF

775 and RSF models. We created separate models for each species and season. Positive values reflect

776 selection for high values of the covariate.

778 Figure 6. Grizzly bear and wolf relative selection strength and 95\% CI's as a function of distance

779 to town and trail density during summer. We calculated relative selection strength by creating

780 predictions from SSFs while holding all variables constant at their mean except for distance to

781 town, trail density, time of day (Day $=1200$ hours, Night $=2400$ hours , and distance to paved

$782 \operatorname{road}(\mathrm{Near}=0 \mathrm{~km}$ and $\mathrm{Far}=20 \mathrm{~km})$.

784 Figure 7. Connectivity estimates for grizzly bears and wolves around the towns of Banff and

785 Canmore under current and future footprints of anthropogenic development. We estimated

786 connectivity by comparing the number of simulated paths that crossed transects under current

787 and future conditions to crossing rates from reference conditions. We simulated 200,000 paths

788 for each species, season, and time period. On average, connectivity decreased from Current to

789 Future for grizzly bears by $6.5 \%$, and, wolves by $5.1 \%$. Grizzly bears have no connectivity

790 estimates while they hibernation in winter. 
792 Figure 8. Habitat degradation measured as the decrease in proportion of high quality habitat from

793 reference to current and future time periods. We estimated habitat degradation for the Bow

794 Valley between Banff and Canmore, Alberta, Canada

795 


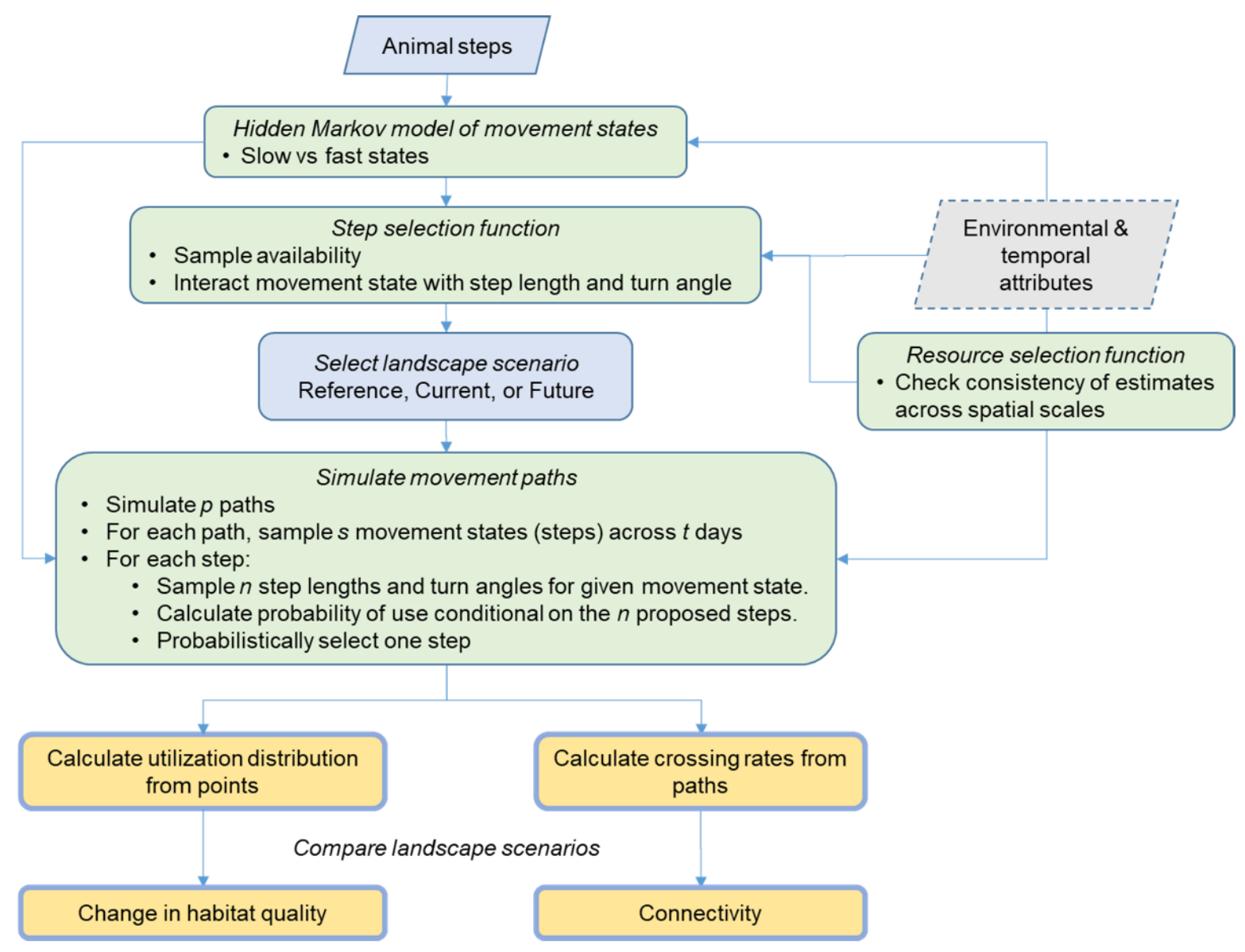

798 Figure 1 . Workflow to assess connectivity and change in habitat quality using hidden Markov

799 models, SSFs, and RSFs. We classified movement behaviors into slow and fast states and then

800 used those states in SSF models and in path simulations. Simulated points can be used to

801 estimate UDs and changes in habitat quality. Connectivity can be measured by comparing

802 movement rates through corridors, across transects, or between patches relative to a reference

803 model of movement with no anthropogenic development. 
bioRxiv preprint doi: https://doi.org/10.1101/2021.02.24.432739; this version posted February 25, 2021. The copyright holder for this preprint (which was not certified by peer review) is the author/funder, who has granted bioRxiv a license to display the preprint in perpetuity. It is made available under aCC-BY-NC-ND 4.0 International license.
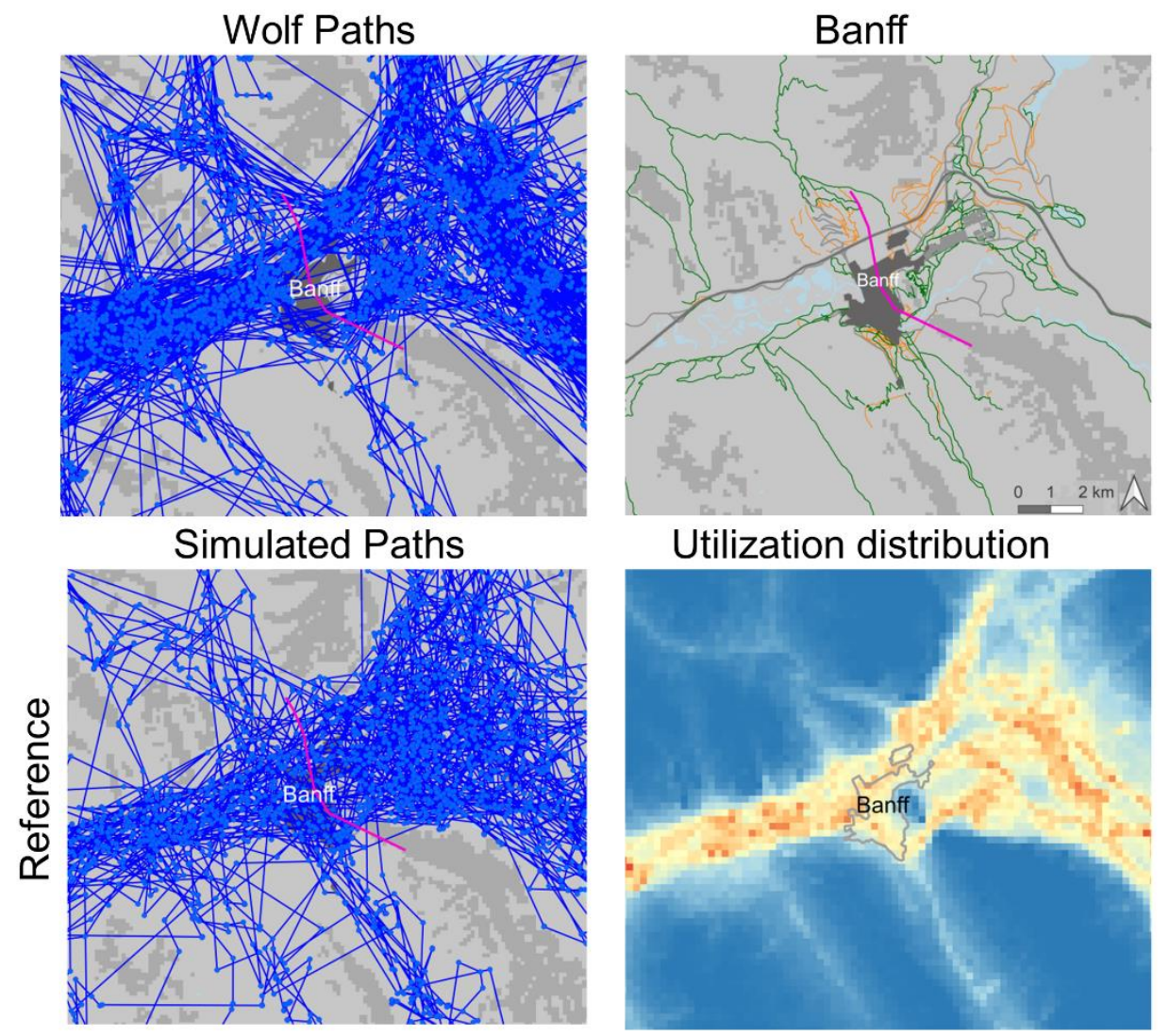

\section{Linear features \\ - Transect \\ - Road \\ - Trail Formal \\ - Trail Informal}
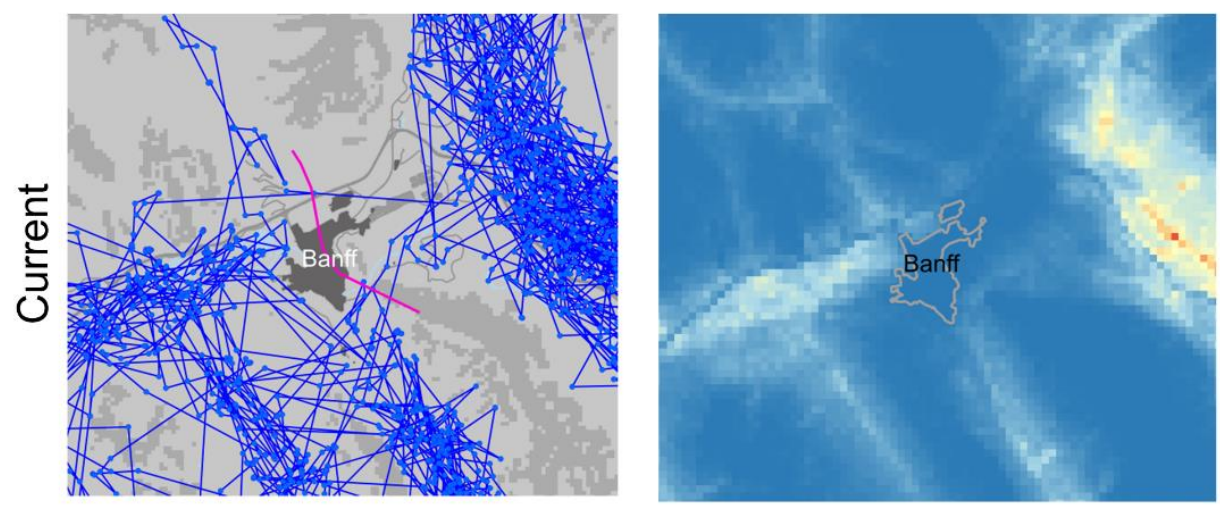

\section{Development \\ - Current \\ - Future \\ Water \\ - Rock}
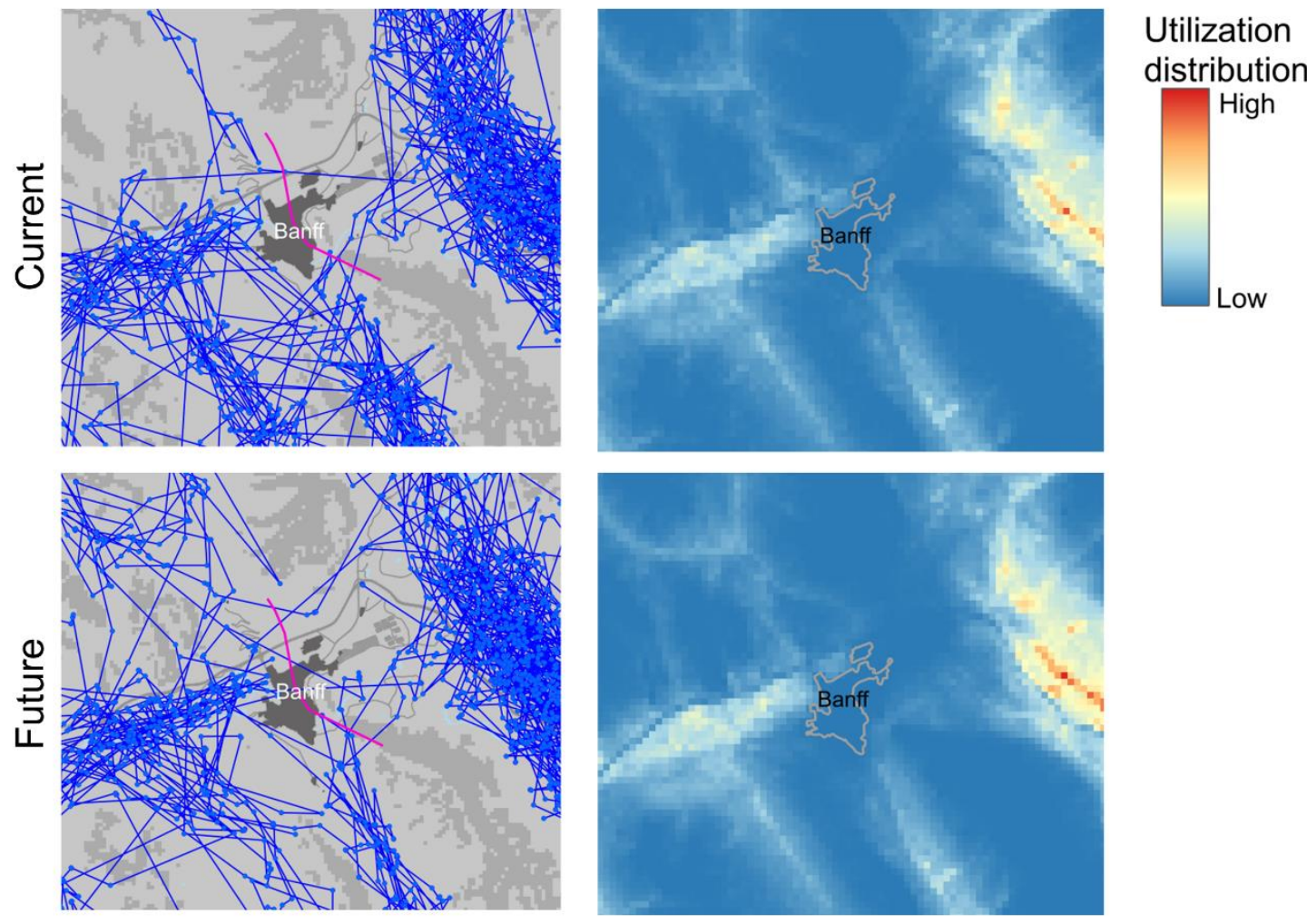
805 Figure 2. Illustration of our connectivity modeling approach in Figure 1 for one species (wolf)

806 and one season (summer) showing the distribution of observed wolf paths around the town of

807 Banff, a random sample of simulated paths under three land use scenarios, and expected

808 utilization distribution. We used hidden Markov models and SSFs to simulate 200,000

809 movement paths across a two-month window. We tallied the number of paths that crossed the

810 valley wide transect and calculated connectivity as the ratio of current to reference and future to

811 reference crossing frequencies. We further quantified habitat degradation as changes in the area

812 of high quality habitat relative to reference conditions. 
bioRxiv preprint doi: https://doi.org/10.1101/2021.02.24.432739; this version posted February 25, 2021. The copyright holder for this preprint (which was not certified by peer review) is the author/funder, who has granted bioRxiv a license to display the preprint in perpetuity. It is made available under aCC-BY-NC-ND 4.0 International license.
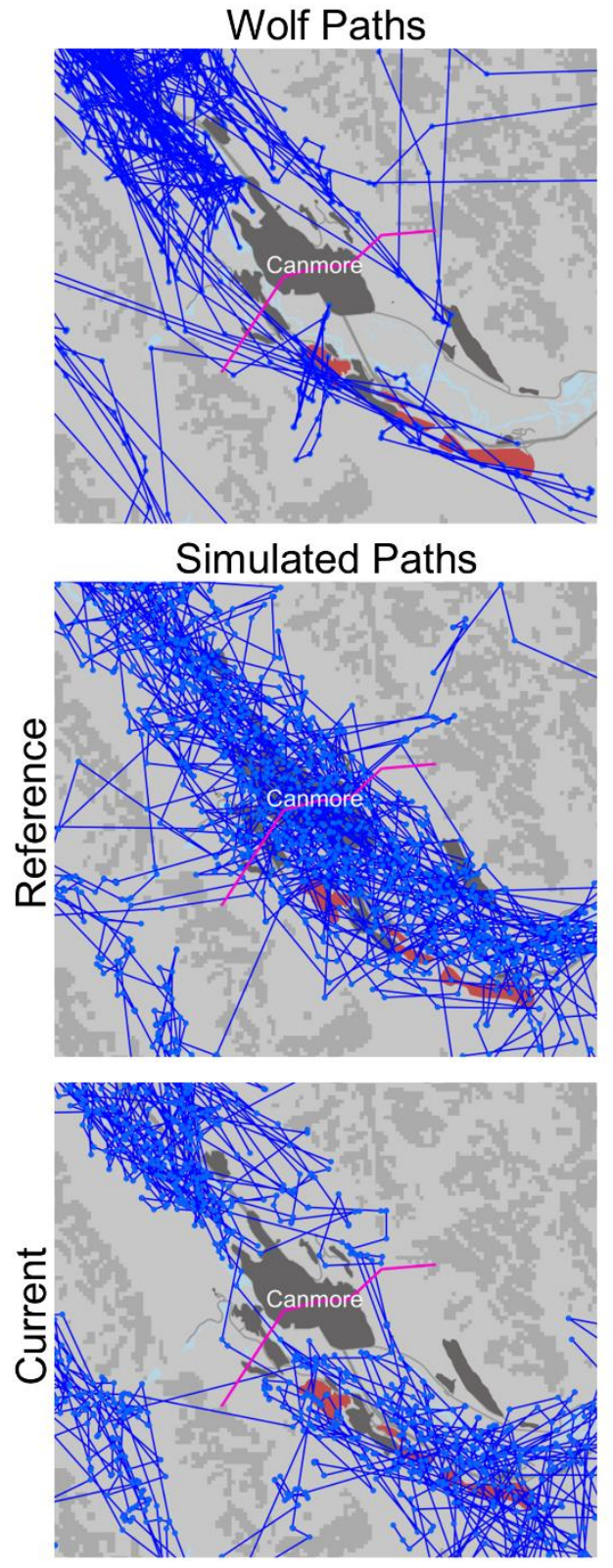

813

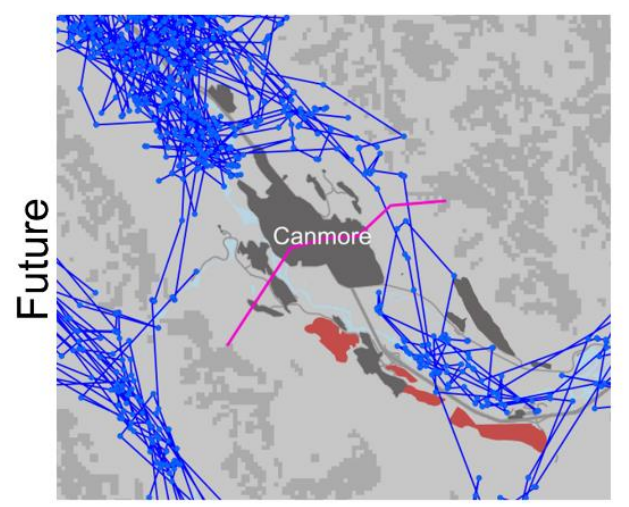

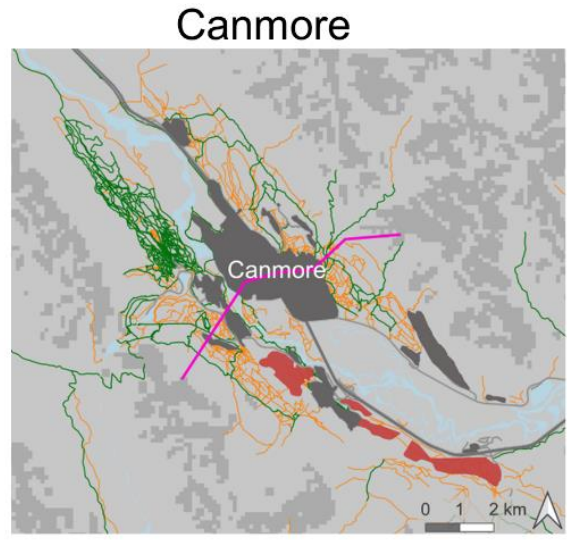

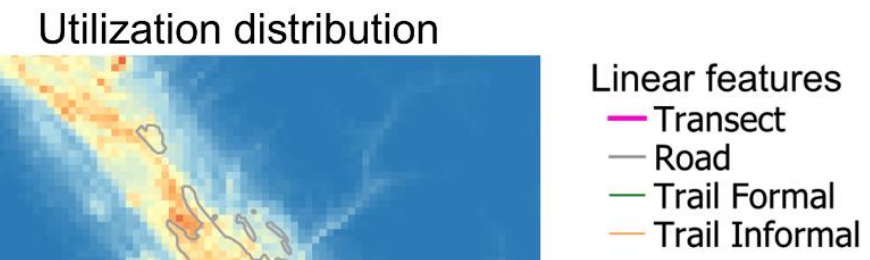

Development

c Current

Future

Water

Rock
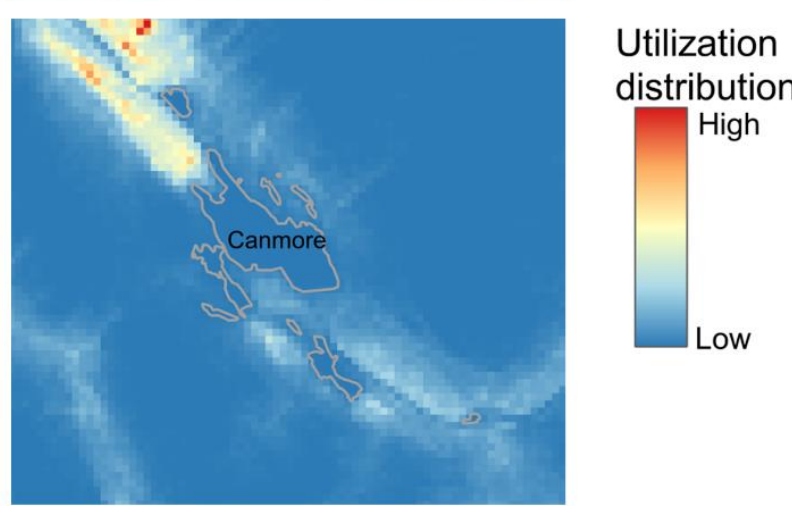

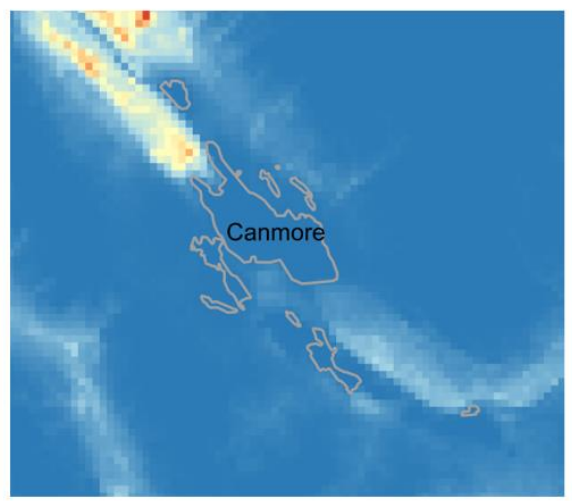


814 Figure 3. Illustration of our connectivity modeling approach in Figure 1 for one species (wolf)

815 and one season (summer) showing the distribution of observed wolf paths around the town of

816 Canmore, a random sample of simulated paths under three land use scenarios, and expected

817 utilization distribution. 


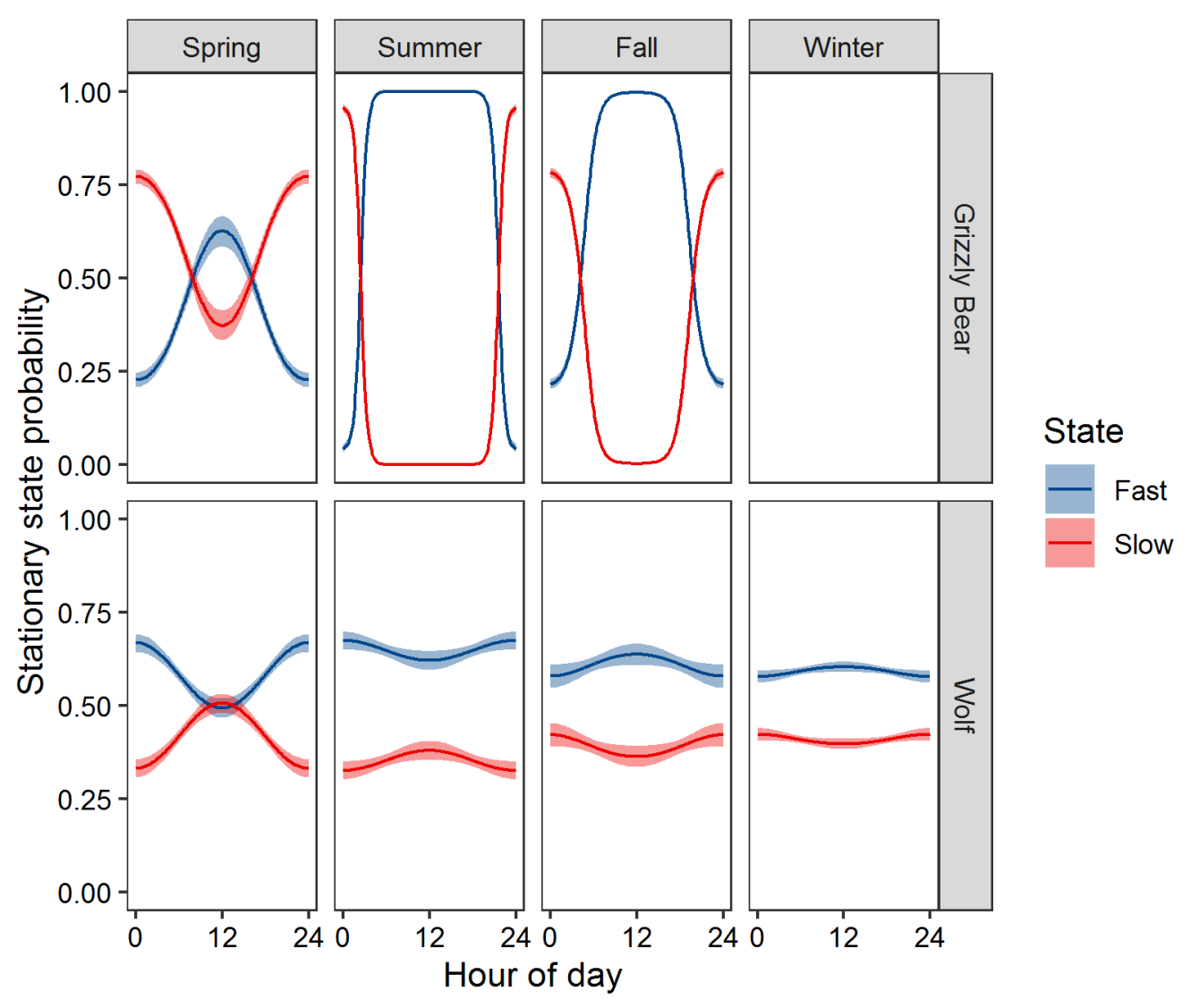

820 Figure 4. Grizzly bear and wolf movement state probabilities (slow versus fast movements) and

$82195 \%$ CI's depended on time of day. Movement states were predicted from hidden Markov

822 models developed from GPS locations. Slow and fast states are interpreted to represent feeding-

823 resting and travel behaviours, respectively. 

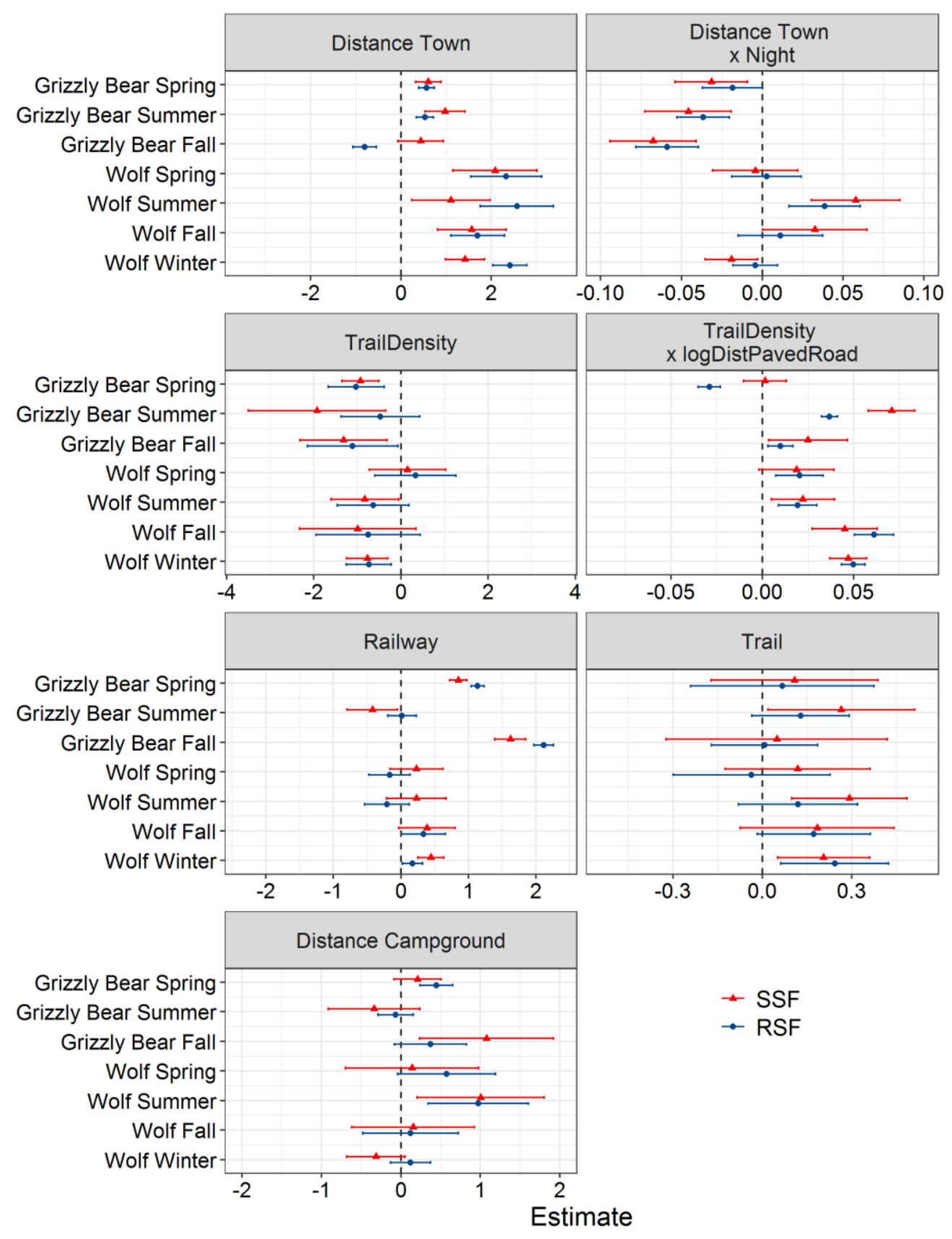

825

826 Figure 5. Human use related parameter estimates and 95\% CI's from grizzly bear and wolf SSF

827 and RSF models. We created separate models for each species and season. Positive values reflect

828 selection for high values of the covariate. 


\section{Distance to town}

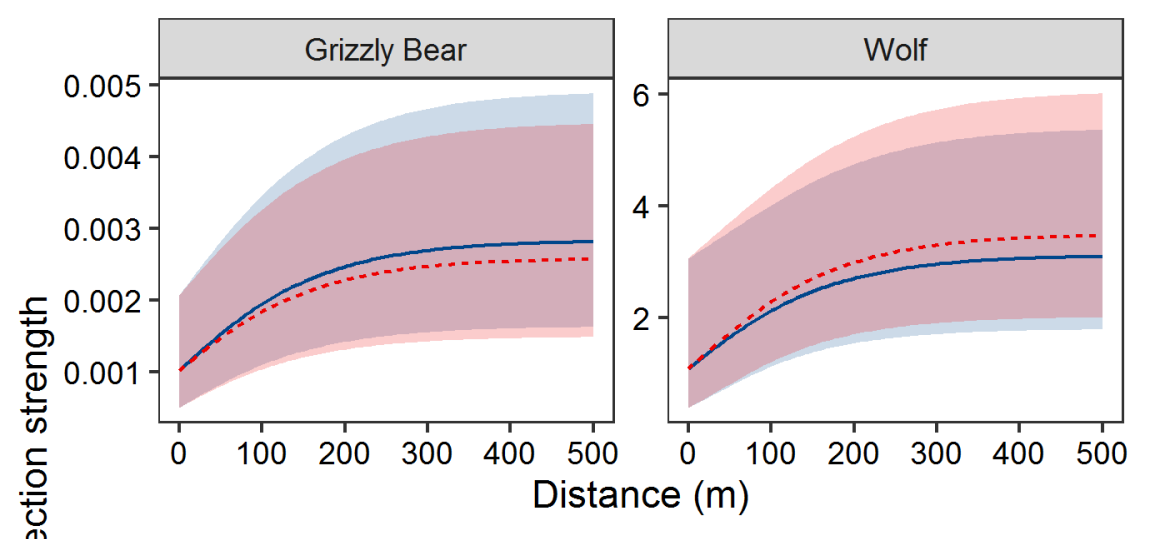

\section{Trail density}

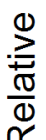

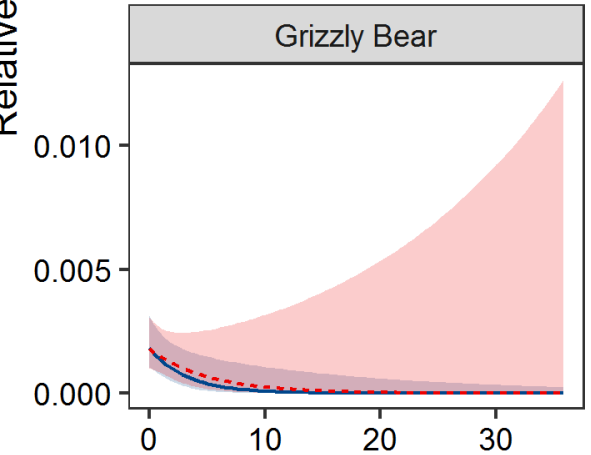

Density $\left(\mathrm{km} \mathrm{km}^{-2}\right)$

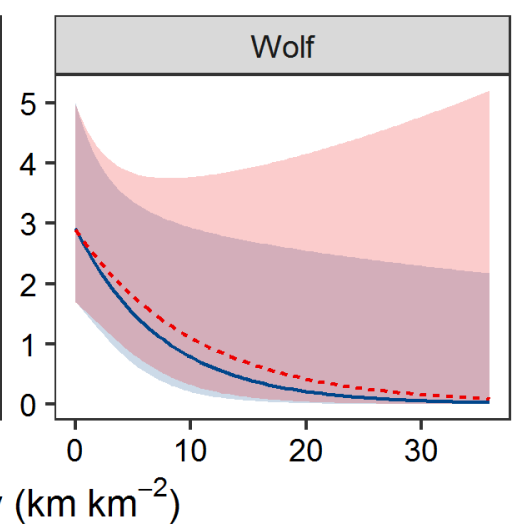

Time

Day

Night

\section{DistanceRoad}

Near

Far

831 Figure 6. Grizzly bear and wolf relative selection strength and 95\% CI's as a function of distance

832 to town and trail density during summer. We calculated relative selection strength by creating

833 predictions from SSFs while holding all variables constant at their mean except for distance to

834 town, trail density, time of day (Day $=1200$ hours, Night $=2400$ hours), and distance to paved

$835 \operatorname{road}(\mathrm{Near}=0 \mathrm{~km}$ and $\mathrm{Far}=20 \mathrm{~km})$. 


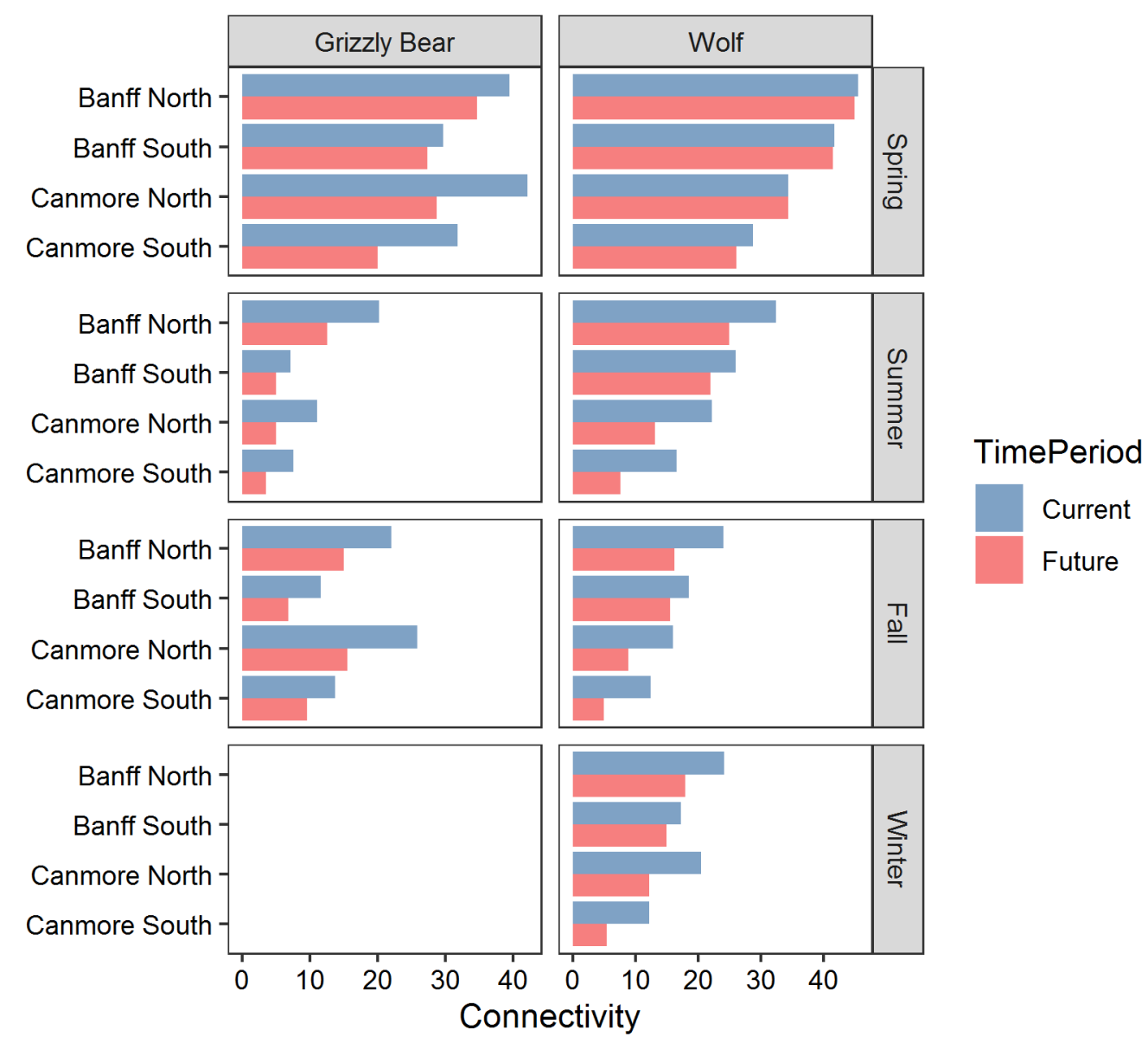

838 Figure 7. Connectivity estimates for grizzly bears and wolves around the towns of Banff and

839 Canmore under current and future footprints of anthropogenic development. We estimated

840 connectivity by comparing the number of simulated paths that crossed transects under current

841 and future conditions to crossing rates from reference conditions. We simulated 200,000 paths

842 for each species, season, and time period. On average, connectivity decreased from Current to

843 Future for grizzly bears by $6.5 \%$, and, wolves by $5.1 \%$. Grizzly bears have no connectivity

844 estimates while they hibernation in winter. 


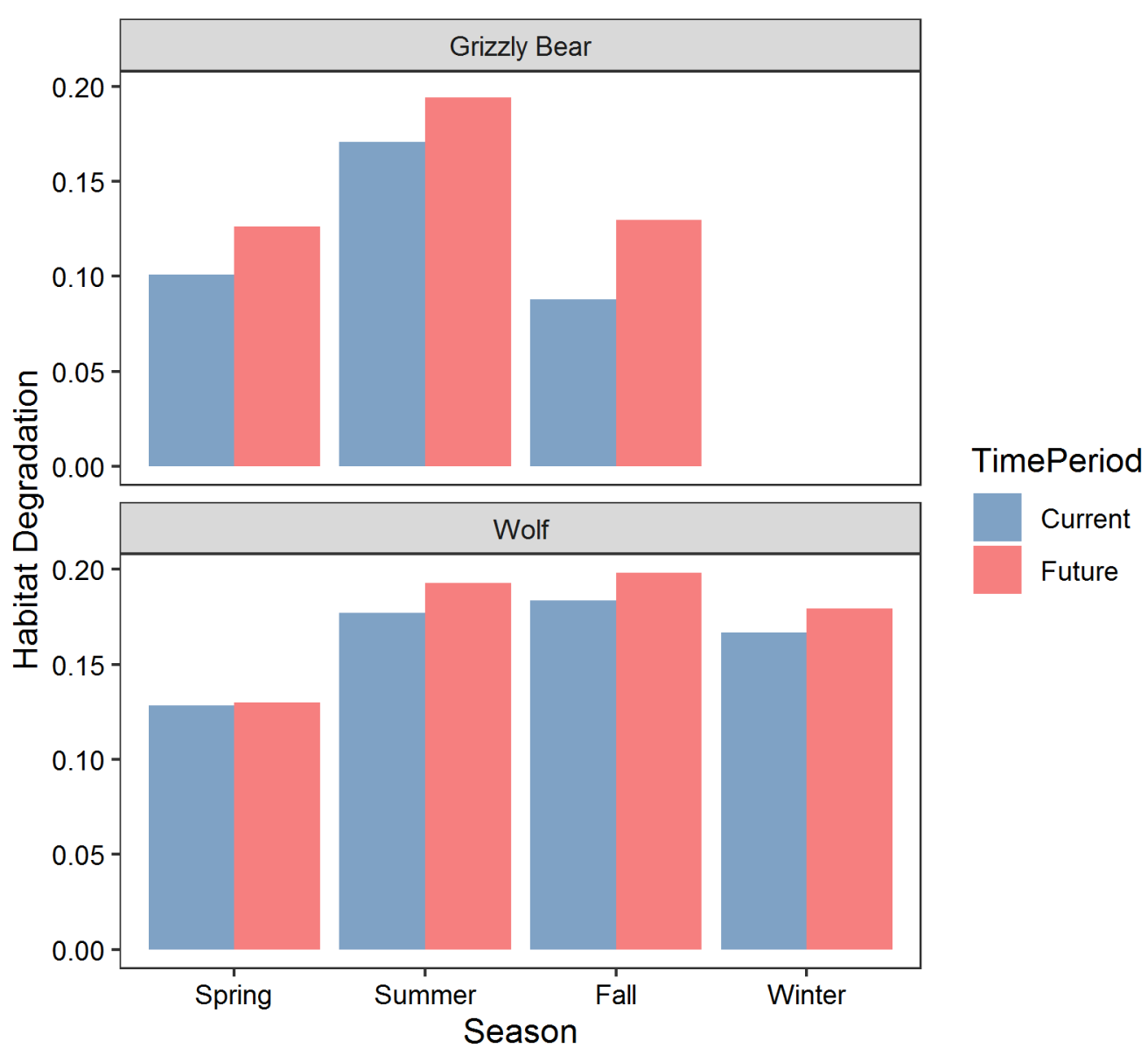

847 Figure 8. Habitat degradation measured as the decrease in proportion of high quality habitat from

848 reference to current and future time periods. We estimated habitat degradation for the Bow

849 Valley between Banff and Canmore, Alberta, Canada. 